\section{(6) OPEN ACCESS}

\title{
Development of patient-centred standards of care for osteoarthritis in Europe: the eumusc.net-project
}

\author{
Michaela A Stoffer, ${ }^{1}$ Josef S Smolen, ${ }^{1}$ Anthony Woolf, ${ }^{2}$ Ales Ambrozic, ${ }^{3}$ \\ Florian Berghea, ${ }^{4}$ Annelies Boonen, ${ }^{5}$ Ailsa Bosworth, ${ }^{6}$ Loreto Carmona, ${ }^{7}$ \\ Maxime Dougados, ${ }^{8,9,10}$ Maarten de Wit, ${ }^{11}$ Josephine Erwin, $^{2}$ \\ Veronika Fialka-Moser, ${ }^{12}$ Ruxandra Ionescu, ${ }^{4}$ Anne-Maree Keenan, ${ }^{13}$ Estibaliz Loza, ${ }^{7}$ \\ Rikke H Moe, ${ }^{14}$ Rolf Greiff, ${ }^{15}$ Pawel Olejnik, ${ }^{16}$ Ingemar F Petersson, ${ }^{17}$ \\ Anne-Christine Rat, ${ }^{18}$ Blaz Rozman, ${ }^{3}$ Britta Strömbeck, ${ }^{17}$ Lorraine Tanner, $^{6}$ \\ Till Uhlig, ${ }^{14}$ Theodora P M Vliet Vlieland, ${ }^{19}$ Tanja A Stamm, ${ }^{1}$ The eumusc.net \\ WP 5 Expert Panel
}

\begin{abstract}
- Additional material is published online only. To view please visit the journal online (http://dx.doi.org/10.1136/ annrheumdis-2014-206176)

For numbered affiliations see end of article.

\section{Correspondence to} Dr Tanja Stamm, Department of Internal Medicine III, Division of Rheumatology, Medical University of Vienna Währinger Gürtel 18-20, Vienna A-1090, Austria; tanja.stamm@meduniwien.ac.
\end{abstract}

Received 29 June 2014 Revised 6 September 2014 Accepted 20 September 2014 Published Online First 21 November 2014

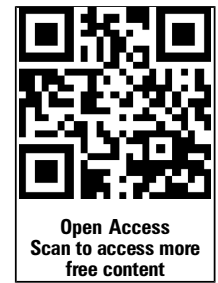

CrossMark

To cite: Stoffer MA, Smolen JS, Woolf $A$, et al. Ann Rheum Dis

2015;74:1145-1149.

\section{ABSTRACT}

Objective The eumusc.net project is an initiative founded by the European Community and the European League Against Rheumatism. One aim of the project was to facilitate equal standards for musculoskeletal health across Europe. The aim of this work-package was to develop patient-centred and consensus based standards of care (SOC) for osteoarthritis (OA), which should be available in a professional and a patient version.

Methods A systematic review concerning guidelines dealing with OA was conducted. Furthermore, experts in musculoskeletal diseases were contacted to ensure that 'grey' literature was not excluded. Documents that fulfilled predefined inclusion/exclusion criteria were included and all interventions for OA were extracted and categorised. Based on this list of interventions, a three round Delphi exercise with an international and multidisciplinary expert panel, including patient research partners, was performed to achieve expert consensus.

Results Six documents were included and used for further analysis. Out of them, 46 interventions have been extracted and 10 consensus based SOC were formulated. In addition, a patient version, written in a layunderstandable wording and in the format of checklist questions was developed. An example is SOC 5: "People with OA should achieve optimal pain control using pharmacological and non-pharmacological means." The matching patient-centred checklist question reads: "Do I know how to control pain associated with OA?" Conclusions The SOC for OA will be available in the 23 languages of the European Union to enhance unified information to patients and professionals and to further harmonise the treatment/care of OA within Europe.

\section{INTRODUCTION}

Osteoarthritis (OA) is a highly prevalent, progressive, degenerative joint disorder leading to pain, stiffness, disability, reduction in quality of life and limitations in the activities of daily living; it is characterised by loss of cartilage, changes in subchondral bone and abnormalities in other joint tissues, such as the synovial membrane and ligaments. Mechanical, biochemical and genetic factors are well known risk factors. ${ }^{1-3} \mathrm{OA}$ is one of the most prevalent musculoskeletal conditions. Its incidence increases in both genders with age and its impact on quality of life can be very high. ${ }^{2}$ Since the occurrence of $\mathrm{OA}$ will increase in the future with the demographic development and aging of the society it constitutes a large and rising economic factor for the health system with high direct and indirect costs. ${ }^{2}{ }^{4}$ Even though currently no disease modifying therapies are known, availability and application of consensus based, cost conscious, effective treatment is highly desirable. This can be partly achieved through guidelines, which can then improve healthcare delivery.

Clinical Practice Guidelines are systematically developed statements assisting in decisions about appropriate healthcare for specific clinical circumstances. ${ }^{6}$ Standards of care (SOC) are defined as 'standards of quality' that are authoritative statements of minimum and/or excellent levels of performance or results. The use of the expression 'standard' creates a doubt between minimum or optimal care. Therefore this should be explicitly described as an attribute of the SOC. The aim of the guidelines is to support decision making; in contrast, the intention of SOC is evaluating practice. Therefore the terms should not be used synonymously. ${ }^{6}$ In this project the aim was to develop a SOC as a minimum SOC acceptable in European countries but not to develop a guideline.

Patients with a chronic disease indicate the need for information about their disease. ${ }^{7}$ At the moment little is known about the impact of guidelines and SOC and their accessibility (as regards obtainment and comprehensibility) for patients. It is recommended that authors of guidelines develop a version that can be understood by the average patient. ${ }^{6}$ However, this requirement is not universally realised.

In the European Musculoskeletal Conditions Surveillance and Information Network (eumusc. net) clinical practice guidelines are identified and appraised. Such activity has already been finalised for rheumatoid arthritis. ${ }^{9}$ Using an expert panel of patients and clinicians from across Europe, we have developed a SOC for OA and additionally a layfriendly version of the SOC is provided. 


\section{SUBJECTS AND METHODS}

A literature search, including a critical appraisal of guidelines, was performed, followed by a three round Delphi exercise with European experts in the field of OA, in order to develop a SOC for OA that is applicable and acceptable in the whole of Europe.

\section{Identification of guidelines}

A systematic literature review was performed in various databases: Guideline registers, Medline, CINAHL and the Internet (Google), between February 2010 and August 2010, using the following keywords: "clinical practice guideline", "guideline", "guidance", "recommendation", "standard of care", "osteoarthritis", and all names of European countries. The reference lists were searched for further relevant publications.

'Grey literature' (American English 'gray literature'), is also known as 'fugitive literature' aimed to produce nonconventional publications. Therefore, these sources are rarely included in bibliographical retrieval systems and it is not mandatory for them to have undergone a peer review process. Nevertheless, these documents could contribute new findings and important information in the context of our study. ${ }^{10}$ In order not to exclude possible 'grey' literature, national societies, health professional associations and patient organisations in 44 countries were contacted and asked to provide relevant national documents for this study.

\section{Inclusion and exclusion criteria}

In this study, guidelines published after January 2002 and until August 2010 dealing with hand, hip and knee OA, or dealing with $\mathrm{OA}$ in general, denoted as guidelines or recommendations, with full text written in English or German, were included. Guidelines on non-pharmacological and pharmacological treatment were reviewed in their current version.

Because of the European perspective in this study and considering the differences between healthcare systems in Europe and the USA, only European guidelines with a full text version were considered for the analysis. The decision to focus on European guidelines was reconfirmed by the fact that in different healthcare systems the roles of health professionals vary substantially. It was a consensual agreement of the working group to develop a SOC for hand, hip and knee OA and to exclude the management of OA of the spine. Therefore, guidelines for the management of back pain and/or OA of the spine were not taken into account.

\section{Assessment of methodological quality}

Documents obtained in their full version and fulfilling the above inclusion and exclusion criteria were evaluated using the Appraisal of Guidelines for Research and Evaluation instrument (AGREE) II criteria ${ }^{8}$ to assess the methodological quality. Only guidelines receiving a high score in the overall assessment (4-7 on a 7-point scale) of the AGREE II criteria were used for further analysis to ensure that only high-quality guidelines could influence the content of the SOC.

\section{Data extraction}

All interventions and recommendations to treat $\mathrm{OA}$ mentioned in the included documents were extracted.

\section{Delphi exercise}

Based on the information retrieved from the guidelines, the relevance and availability in different European countries of the extracted interventions were discussed and grouped in a 1-day meeting in Vienna.

The expert panel consisted of 4 patient research partners and 22 health professional experts with extensive experience in clinical and/or scientific work from a total of 17 expert centres for musculoskeletal diseases in 10 European countries. All experts and patient partners are authors of this article. After the meeting a first draft of SOC was developed and sent to the expert panel via email. Each comment of a working group member had the same weight.

Panel members were asked for their agreement with the proposed wording of the SOC and in case of disagreement to suggest an alternative formulation.

The comments of the expert group were built into the next version of the SOC that was circulated again. Furthermore, in this round the experts were asked to score each SOC using a scale of 1-3: $1=$ "A must have for the final set of SOC"; $2=$ "Would be nice to have in the final set of SOC"; $3=$ "Is not important in a final set of SOC". ${ }^{11}$

After including the comments provided by the panel members, the final set of SOC was sent to the expert panel to obtain the level of agreement within the group. Each panel member was asked to score each SOC on a scale from $0(0=$ 'I totally disagree') to 10 ( $10=$ 'I agree completely').

Based on the expert-SOC, we formulated questions for the patient-centred checklist (for each item) aiming for a comprehensive and lay-understandable wording. Each member of the working group could comment on the draft. The final approval of the wording of the patient-centred checklist was made by the patient partners.

The aim of this checklist is to enable patients with OA to clarify if they have all the required information. The checklist can also be the basis for the conversation with health professionals.

\section{Literature search update}

To assure that the SOC are up to date at the time of publication, the literature search was repeated in August 2014 using the same keywords and searching the same databases.

\section{RESULTS}

References were identified from Medline $(\mathrm{n}=697)$, CINAHL $(n=45)$, guideline registers $(n=10)$ and the internet (the first 150 Google hits, without paid hits). A total of 902 references were obtained.

Eighty-seven national scientific societies, patient organisations and health professional associations in 44 countries were contacted and after sending up to three reminder emails, we achieved a response rate of $63 \%$. Excluding duplicates, the European organisations provided 14 documents. Among the documents provided by the national societies, health professional associations and patient organisations, 12 documents have been excluded because they were written in the national language and there was no translation available (Croatia $\mathrm{n}=1$, Estonia $n=1$, Finland $n=1$, Hungary $n=1$, Israel $n=1$, Italy $\mathrm{n}=1$, Moldavia $\mathrm{n}=2$, Netherlands $\mathrm{n}=1$, Poland $\mathrm{n}=1$, Slovakia $\mathrm{n}=1$, Sweden $\mathrm{n}=1$ ).

The titles and/or abstracts of the 916 documents were reviewed. Of these, 873 were excluded for not being a guideline or a recommendation. Full texts of 43 documents were reviewed. Thereafter, additional 37 documents were excluded because of non-European origin, failing to fulfil methodical requirements, or in a language different from English or German. 
Ultimately, six documents ${ }^{12-17}$ fulfilled the inclusion/exclusion criteria and were used for the final analysis. From these guidelines 46 interventions, such as exercise or appropriate pain control, could be extracted. All recommendations presented in the retrieved guidelines have been excerpted and accordingly linked with the interventions found in the previous step.

\section{Results Delphi Round 1}

The working group meeting was held in September 2010 in Vienna and was attended by 16 (62\%) experts from the expert panel. In this meeting, the 46 interventions and/or methods were critically revised and classified into four groups (representing the main treatment modalities in OA): (1) Education, information and self-management (2) Pharmacological treatment (3) Non-pharmacological treatments (rehabilitative interventions and lifestyle interventions) (4) Surgical treatment.

During the meeting, the relevance and availability of some interventions recommended in the various guidelines were discussed. For example, we categorised the interventions "application of heat, appliance of paraffin wax, use of local heat or cold" under the term "thermotherapy". Thereafter, we agreed that this intervention is relevant for the treatment of OA and in a second step we determined if the respective intervention is generally deliverable in the countries represented in the working group.

The first proposed scheme was visualised on a mind map and each working group member had the option to propose statements in the form of one sentence to summarise the content. During the whole development process the working group was instructed to focus on clear and easy statements. A draft of 8 SOC in the format of short sentences was formulated. This draft version was sent to the whole expert panel.

\section{Results Delphi Round 2}

In the second Delphi round, we received feedback from 18 $(69 \%)$ experts, consisting of 60 comments. These were used to formulate the second draft of the SOC. The rearrangement of the SOC led to a version consisting of 10 SOC.

\section{Results Delphi Round 3}

We then received 34 comments from 14 (54\%) experts in the third Delphi round. The importance of each SOC was rated by $18(69 \%)$ experts.

The inclusion of the comments from the third Delphi round resulted in the final version of the SOC (table 1).

Based on the 'expert-SOC', a patient version in the format of a checklist was formulated with the intention that it should be easy to understand for lay people (table 2).

The Level of Agreement of the SOC was rated by $21(81 \%)$ experts and was between 9.3 and 9.9 on a scale $0-10$, as shown in the last column of table 1.

While the search focused on the English and German literature for practical reasons, the SOC and the patient version will be available in all 23 languages of the European Union online and will also be distributed widely with the support of the patient organisations aiming to spread the information and to overcome language barriers.

Table 1 Standards of care for people with osteoarthritis

\begin{tabular}{|c|c|c|}
\hline & & $\begin{array}{l}\text { Level of } \\
\text { agreement }\end{array}$ \\
\hline SOC 1 & People with symptoms of OA should have access to a health professional competent in making a (differential) diagnosis. & 9.9 \\
\hline SOC 2 & $\begin{array}{l}\text { People with symptoms of OA should be assessed at diagnosis and upon significant worsening for } \\
\text { Pain } \\
\text { Function } \\
\text { Physical activity } \\
\text { BMI } \\
\text { - Ability to do their tasks and work }\end{array}$ & 9.5 \\
\hline SOC 3 & People with OA should receive a treatment plan with a shared treatment target set between them and a health professional. & 9.3 \\
\hline SOC 4 & $\begin{array}{l}\text { People with OA should have access to different health professionals such as occupational therapist and physiotherapist if needed to treat their } \\
\text { symptoms and achieve optimal possible functioning in daily life and participation in social roles (including paid work). }\end{array}$ & 9.4 \\
\hline SOC 5 & People with OA should achieve optimal pain control using pharmacological and non-pharmacological means. & 9.7 \\
\hline SOC 6 & People with OA should achieve optimal function using pharmacological and non-pharmacological means. & 9.7 \\
\hline SOC 7 & People with OA receiving NSAID or aspirin therapy should be assessed for GI bleeding risk, CVD risks and renal risks. & 9.6 \\
\hline SOC 8 & $\begin{array}{l}\text { People with } \mathrm{OA} \text { should receive information tailored to their needs within } 3 \text { months of diagnosis by health professionals about } \\
\text { their disease and all aspects of living with and managing their } \mathrm{OA} \text {, in written form and in a format suited and tailored to the individual, in a } \\
\text { timely fashion appropriate to their needs; } \\
\text { the benefit of exercises and physical activity and should be instructed to exercise appropriately; } \\
\text { aids, devices and other products for environmental adaptations; } \\
\text { ergonomic principles and activity-based methods to enhance functioning in daily life and participation in social roles; } \\
\text { the importance of an ideal body weight; } \\
\text { the role of analgesics - their potential benefits and risks; } \\
\text { sleep disturbance if necessary); } \\
\text { prevention of accidents and injuries; } \\
\text { support groups and patient organisations; } \\
\text { when to think about surgery; }\end{array}$ & 9.5 \\
\hline SOC 9 & People with $\mathrm{OA}$ should receive information about weight reduction if necessary. & 9.8 \\
\hline SOC 10 & $\begin{array}{l}\text { People with } \mathrm{OA} \text { failing to respond to pharmacological and non-pharmacological therapy should be considered for surgical intervention. If referred, } \\
\text { they should be seen by an orthopaedic surgeon within a reasonable time. }\end{array}$ & 9.5 \\
\hline
\end{tabular}


Table 2 What this means for you and your osteoarthritis...

\begin{tabular}{|c|c|}
\hline 1 & Was my OA diagnosed by a health professional? \\
\hline 2 & Do I have regular assessment concerning my symptoms and functioning in daily life? \\
\hline 3 & Do I have a treatment target and a corresponding treatment plan? \\
\hline 4 & $\begin{array}{l}\text { Do I have the opportunity to receive support if needed from health professionals such as rheumatologist, dietician, general practitioner, nurse, } \\
\text { occupational therapist, physiotherapist, psychologist and social worker? }\end{array}$ \\
\hline 5 & Do I know how to control pain associated with OA? \\
\hline 6 & Do I know how to maximise my physical function despite having $O A$ ? \\
\hline 7 & Have I been assessed for any risks associated with my treatment? \\
\hline 8 & $\begin{array}{l}\text { Do I understand my disease and my role in its management? } \\
\text { Have I been offered information in different formats and/or education about my disease? } \\
\text { Have I been informed about living with and managing my OA? } \\
\text { Have I been informed about a healthy lifestyle? } \\
\text { Have I been informed about exercises specific for me? } \\
\text { Have I been informed about pain relieving medication-the benefits and potential risks? } \\
\text { Do I know what benefit I can have from my exercise program? } \\
\text { Have I been informed and did I receive advice and training on aids, devices and ergonomic principles to enhance function in daily life and } \\
\text { participation in social roles? }\end{array}$ \\
\hline 9 & If my BMI is $>27$, have I been informed about weight reduction? \\
\hline 10 & Have I been informed about when surgery should be considered, what it involves, its benefits and risks? \\
\hline
\end{tabular}

\section{Literature search update}

The second literature search provided three additional documents ${ }^{18-20}$ fulfilling the inclusion and exclusion criteria. The recommendations presented in the three documents retrieved in the literature update have been extracted. In the next step, all recommendations given in the guidelines have been linked to the SOC to investigate if they are up to date. This led to a change in the wording of one SOC (SOC number 4). The new wording was checked by the working group and was approved.

\section{DISCUSSION}

To our knowledge, this is the first study that brought together existing OA guidelines to develop an expert and patient-centred SOC for OA. We did not expect that for the large field of OA only a few European guidelines existed. The extent of the available documents also differed largely.

In 1966, Donabedian proposed that healthcare quality could be measured by considering the structure, the process and the outcomes of care. ${ }^{21}$ Based on that principle, there has been a trend towards developing national SOC and good practice in many different specialties across the world ${ }^{22} 23$ to raise and harmonise quality of care and enable equity of care. The number of initiatives to define and implement SOC, though increasing, is still low. $^{23} 24$ The aim of this initiative was to develop accepted, consensus-based and patient-centred SOC for persons with $\mathrm{OA}$, to obtain the best quality of care within the resources available, especially in the current context of economic crisis. This document is intended to help and support health professionals involved in OA care as well as patients by providing a statement of SOC requirements. It can also act as the formal record of SOC as part of the clinical governance process of any rheumatology unit and health system.

In addition to pharmacological treatment, nonpharmacological methods delivered by health professionals such as physiotherapists, occupational therapists and specialists for physical medicine and rehabilitation are necessary. However, while the importance given to non-pharmacological treatment is reflected in the guidelines, high-quality evidence, except for knee OA, is scarce. This could be a result of the difficulty of conducting and funding high-quality randomised controlled trials for non-pharmacological treatments and because OA might not be seen as a high priority in funding institutions. Thus, further research in this area is urgently required to assess the evidence for these interventions.

The focus of the eumusc.net project was to investigate the musculoskeletal health status in Europe (in work-package 4), to develop SOC (in work-package 5), Quality Indicators (in workpackage 6$)^{25} 26$ and to identify "facilitators and barriers" for implementing the SOC (in work-package 7). ${ }^{27}$ To help implementation of the SOC, they will be presented at the eumusc.net homepage with a link from the European League Against Rheumatism homepage and the national societies will be informed accordingly, asking them to convey the SOC to their members. In addition, a project is planned to bridge the gap between evidence and practice, including an audit of rheumatology centres that agree to participate. The aim of the audit is to evaluate if the SOC are implemented in the daily routine.

The SOC for OA have been developed according to the process that was used for the development of the SOC for rheumatoid arthritis. ${ }^{9}$

The aim of this initiative was to provide a set of questions that patients could use in the consultation of health professionals to facilitate the discussion of the treatment.

While a strength of our study is the provision of consensus based information concerning OA worded in a way that can be easily understood by lay persons including patients, our study also has several limitations: we restricted the included guidelines to those available in English and German language only, we did not conduct an empirical testing and we did not re-evaluate the evidence base of the guidelines. Even if the interventions were retrieved from the guidelines, the wording of the SOC was a consensus within the expert group including the expertise of the patient partners. Also, we did not address OA of the spine, as back pain is different from peripheral joint OA and has a different diagnosis and therapy. It was not the scope of the project to examine the economical feasibility and the validity of the SOC. Further research is suggested to explore these areas. Finally, implementation could not yet be assessed so far. To evaluate this implementation, in another work package, Health Care Quality Indicators have been developed. ${ }^{26}$

The SOC should be a minimum standard for all European countries and, ideally, ought to be implemented as soon as 
possible, but not later than by the year 2020 according to the aims of this European Union project. Furthermore, they are meant to be a resource for interested persons. The checklist presented should give persons without a professional background the ability to clarify what appropriate care is and to facilitate the discussion of the treatment options with their health professionals. With this work, we hope to promote more unification of the treatment of OA throughout Europe.

In summary, in order to improve quality of care in patients with OA, service providers, support groups, policy-makers, patients and health professionals themselves should work together to develop a framework for managing OA. This framework should take account of the chronicity of this disorder and the current changing environment for the delivery of healthcare. This set of SOC will help achieve this goal.

\section{Author affiliations}

${ }^{1}$ Division of Rheumatology, Department of Medicine 3, Medical University of Vienna, Vienna, Austria

${ }^{2}$ Royal Cornwall Hospital, Truro Cornwall, UK

${ }^{3}$ University Medical Centre Ljubljana, Ljubljana, Slovenia

${ }^{4}$ Universitatea de Medicina si Farmacie Carol Davila, Bucharest, Romania

${ }^{5}$ Maastricht University Medical Center, Maastricht, The Netherlands

${ }^{6}$ National Rheumatoid Arthritis Society, Berkshire, UK

${ }^{7}$ Instituto de Salud Musculoesqueletica, Madrid, Spain

${ }^{8}$ Paris Descartes University, Paris, France

${ }^{9}$ Department of Rheumatology-Hôpital Cochin. Assistance Publique-Hôpitaux de Paris, Paris, France

${ }^{10}$ INSERM (U1153): Clinical Epidemiology and biostatistics, PRES Sorbonne ParisCité, Paris, France

${ }^{11}$ Reumapatientenbond, Amersfoort, The Netherlands

${ }^{12}$ Department of Physical Medicine and Rehabilitation, Medical University of Vienna, Vienna, Austria

${ }^{13}$ University of Leeds and NIHR Leeds Musculoskeletal Biomedical Research Unit, Leeds, UK

${ }^{14}$ National Advisory Unit on Rehabilitation in Rheumatology (NKRR), Oslo, Norway

${ }^{15}$ Rheumatikerförbundet, Swedish Rheumatism Association, Stockholm, Sweden

${ }^{16}$ Instytut Reumatologii, Warsaw, Poland

${ }^{17}$ Orthopedics and Rheumatology, Clinical Sciences, Lund University, Lund, Sweden

${ }^{18}$ Université de Lorraine, Université Paris Descartes, Apemac, EA 4360, Nancy, France

${ }^{19}$ Leiden University Medical Center, Leiden, The Netherlands

Collaborators Work panel members affiliations are shown in online supplementary appendix A.

Contributors MAS, JSS, TAS: conception and design; analysis and interpretation of data; drafting the article and revising it critically for content, with all authors involved in the revision and final phases. Approval of the final version to be published: All authors were involved.

Funding This study was funded by the European Community (EC Community Action in the Field of Health 2008-2013) together with the European League Against Rheumatism (EULAR). Furthermore, the current study was partly funded by the Austrian Science Fund (FWF): [P21912-B09]. The content of this work was not influenced by the opinion of the funding bodies.

Competing interests AnB has received research grants from AbbVie, Merck, Amgen and an educational grant from Pfizer; none of them relates to this work. IFP has received speaker fees from AbbVie, Pfizer and UCB; none of them relates to this work. JSS has received honoraria from AbbVie, Amgen, BMS, Wyeth, Jansen, Roche, Schering-Plough and Sanofi-Aventis; none of them relates to this work. TAS has received speaker fees from UCB, AbbVie and MSD; none of them relates to this work. TU has received honoraria from MSD and Pfizer; none of them relates to this work. MAS has received speaker fees from MSD; none of them relates to this work.

Provenance and peer review Not commissioned; externally peer reviewed.

Open Access This is an Open Access article distributed in accordance with the Creative Commons Attribution Non Commercial (CC BY-NC 4.0) license, which permits others to distribute, remix, adapt, build upon this work non-commercially, and license their derivative works on different terms, provided the original work is properly cited and the use is non-commercial. See: http://creativecommons.org/licenses/by-nc/4.0/

\section{REFERENCES}

1 Altman R, Asch E, Bloch D, et al. Development of criteria for the classification and reporting of osteoarthritis. Classification of osteoarthritis of the knee. Diagnostic and Therapeutic Criteria Committee of the American Rheumatism Association. Arthritis Rheum 1986:29:1039-49.

2 Reginster JY. The prevalence and burden of arthritis. Rheumatology (Oxford) 2002:41(Supp1):3-6.

3 Pottie P, Presle N, Terlain B, et al. Obesity and osteoarthritis: more complex than predicted! Ann. Rheum Dis 2006;65:1403-5.

4 World Health Organization (WHO). The world health report 2002-Reducing risks, promoting healthy life. Geneva: World Health Organization, 2002; Retrieved 2 May 2010. http://www.who.int/whr/2002/en/whr02_en.pdf

5 Lineker SC, Husted JA. Educational interventions for implementation of arthritis clinical practice guidelines in primary care: effects on health professional behavior. J Rheumatol 2010;37:1562-9.

6 Field MJ, Lohr KH. Clinical practice guidelines: directions for a new program. Washington, DC: Nat. Acad. Press, 1990

7 Drăgoi RG, Ndosi M, Sadlonova M, et al. Patient education, disease activity and physical function: can we be more targeted? A cross sectional study among people with rheumatoid arthritis, psoriatic arthritis and hand osteoarthritis. Arthritis Res Ther 2013;15:R156

8 Appraisal of Guidelines for Research and Evaluation Trust (AGREE) Next Steps. The AGREE II Instrument (Electronic version). 2009; Retrieved 1 June 2012. http:www. agreetrust.org

9 Stoffer MA, Smolen JS, Woolf A, et al. Development of patient-centred standards of care for rheumatoid arthritis in Europe: the eumusc.net project. Ann Rheum Dis 2014:73:902-5

10 Porta M, Greenland S, Last JM. A dictionary of epidemiology. Oxford Univ. Press, 2008.

11 Freel AC, Shiloach M, Weigelt J, et al. American College of Surgeons Guidelines Program: a process for using existing guidelines to generate best practice recommendations for central venous access. J Am Coll Surg 2008:207:676-82.

12 Jordan KM, Arden NK, Doherty M, et al. EULAR Recommendations 2003: an evidence based approach to the management of knee osteoarthritis: report of a Task Force of the Standing Committee for International Clinical Studies Including Therapeutic Trials (ESCISIT). Ann Rheum Dis 2003:62:1145-55.

13 Zhang W, Doherty M, Arden N, et al. EULAR evidence based recommendations for the management of hip osteoarthritis: report of a task force of the EULAR Standing Committee for International Clinical Studies Including Therapeutics (ESCISIT). Ann Rheum Dis 2005;64:669-81.

14 Zhang W, Doherty M, Leeb BF, et al. EULAR evidence-based recommendations for the diagnosis of hand osteoarthritis: report of a task force of ESCISIT. Ann Rheum Dis 2009:68:8-17.

15 Deutsche Gesellschaft für Orthopädie und Orthopädische Chirurgie (DGOOC) und des Berufsverbandes der Ärzte für Orthopädie (BVO). 2009; Leitlinie Koxarthrose Retrieved 2 May 2010. http://www.awmf.org/uploads/tx_szleitlinien/033-001_S3_ Koxarthrose 11-2009_11-2014.pdf

16 Zhang W, Nuki G, Moskowitz RW, et al. OARSI recommendations for the management of hip and knee osteoarthritis: Part III: Changes in evidence following systematic cumulative update of research published through january 2009. Osteoarthritis Cartilage 2010;18:476-99.

17 National Collaborating Centre for Chronic Conditions. Osteoarthritis: national clinical guideline for care and management in adults. London: Royal College of Physicians, 2008; Retrieved 1 January 2012. http://www.nice.org.uk/nicemedia/live/11926/ 39720/39720.pdf

18 Fernandes L, Hagen KB, Bij|sma JWJ, et al. EULAR recommendations for the non-pharmacological core management of hip and knee osteoarthritis. Ann Rheum Dis 2013;72:1125-35.

19 McAlindon TE, Bannuru RR, Sullivan MC, et al. OARSI guidelines for the non-surgical management of knee osteoarthritis. Osteoarthritis Cartilage 2014;22:363-88.

20 Peter WF, Jansen MJ, Hurkmans EJ, et al. Physiotherapy in hip and knee osteoarthritis: development of a practice guideline concerning initial assessment, treatment and evaluation. Acta Reumatol Port 2014;36:268-81.

21 Donabedian A. Evaluating the quality of medical care. 1966. Milbank Q 2005:83:691-729.

22 Rodeheaver GT. The US model for national standards of care. I Wound Care 1995:4:238-9.

23 Kennedy T, Mccabe C, Struthers G, et al. BSR guidelines on standards of care for persons with rheumatoid arthritis. Rheumatology (Oxford) 2005:44:553-6.

24 Davies K, Cleary G, Foster H, et al. BSPAR Standards of Care for children and young people with juvenile idiopathic arthritis. Rheumatology (Oxford) 2010;49:1406-8.

25 Petersson IF, Strömbeck B, Andersen L, et al. Development of healthcare quality indicators for rheumatoid arthritis in Europe: the eumusc.net project. Ann Rheum Dis 2014;73:906-8.

26 Petersson IF, Strömbeck B, Andersen L, et al. Development of Health Care Quality Indicators for Osteoarthritis in Europe: the eumusc.net project. (Submitted 2014).

27 Moe RH, Petersson IF, Carmona L, et al. Facilitators to implement standards of care for rheumatoid arthritis and osteoarthritis: the EUMUSC.NET project. Ann Rheum Dis 2014;73:154-85. 